Article

\title{
An Evaluation of Soil Moisture Anomalies from Global Model-Based Datasets over the People's Republic of China
}

\author{
Daniel Fiifi Tawia Hagan ${ }^{1}$, Robert M. Parinussa ${ }^{1}$, Guojie Wang ${ }^{1, *(1)}$ and Clara S. Draper ${ }^{2}$ \\ 1 Collaborative Innovation Center on Forecast and Evaluation of Meteorological Disasters, School of \\ Geographical Sciences, Nanjing University of Information Science \& Technology, Nanjing 210044, China; \\ dhagan@ucar.edu (D.F.T.H.); r_parinussa@hotmail.com (R.M.P.) \\ 2 Cooperative Institute for Research in Environmental Sciences, University of Colorado Boulder Physical \\ Sciences Division, NOAA/Earth System Research Laboratory, Boulder, CO 80305, USA; \\ clara.draper@noaa.gov \\ * Correspondence: gwang@nuist.edu.cn; Tel.: +86-25-5873-1418
}

Received: 26 November 2019; Accepted: 27 December 2019; Published: 30 December 2019

\begin{abstract}
Soil moisture is an important factor in land-atmosphere interactions and other land processes. Improved estimates from climate models have, in the last two decades, become an important alternate source of information. In this study, we extend the evaluation of soil moisture anomalies of different generations of three families of model datasets (the European Center for Medium-Range Weather Forecasts' (ECMWF) reanalysis, the Modern Era Retrospective Analysis for Research and Applications of NASA, and the Global Land Data Assimilation System of theNational Oceanic and Atmospheric Administration (NOAA)) in recent studies to the People's Republic of China. Two validation techniques, namely, root-mean-square error (RMSE) from triple collocation analysis (TCA) and correlations (R) with ground observations, were used. The study confirmed the results of previous studies that focused on other regions and showed that the newer generations of each modeling family generally had better skill than the older generations with higher correlations and lower RMSEs. A cross-validation of the results from the two techniques for the newer products showed that the higher correlations and lower RMSEs from the TCA were found over regions with moderate vegetation cover, while regions with less vegetation cover had lower correlations and larger RMSEs (ECMWF (R: -0.93), NASA (R: -0.73), and NOAA (R: -0.61)), indicating that these two techniques complement each other to fairly validate the products.
\end{abstract}

Keywords: soil moisture; reanalysis; triple collocation; Essential Climate Variable

\section{Introduction}

In climate, weather, and hydrological systems, surface soil moisture plays an important role as it regulates the terrestrial water and energy cycles. There are numerous studies that have linked the impact of soil moisture anomalies to land-atmosphere interactions [1-3] and extreme events such as flooding and heat waves [4], as well as weather and climate monitoring in operational services [5]. It has, therefore, become significantly important to properly monitor soil moisture globally and regionally. The traditional approach to taking soil moisture measurements has been through ground stations that produce point-scale measurements. This approach results in accurate point-scale observations; however, it is generally limited in terms of spatial extent and can be more useful over small regions. Over regional and global scales, it becomes exceedingly expensive to set up networks to capture consistent spatial and temporal soil moisture estimates. This source of data has thus become very useful in serving as 'ground truth' to validate alternate sources of data, though the high spatial variability of 
the variable should always be considered as a factor when comparing against alternative surface soil moisture products that come at coarser scales [6].

With the advancement of remote sensing technologies, the capacity to monitor surface soil moisture over most of the terrestrial earth surface over larger scales has become more consistent. Different sensors onboard satellites measure emitted radiation and/or reflected backscatter from the earth's surface that can be linked to surface soil moisture conditions. Recently, the use of passive and active microwave imagers to observe soil moisture over large scales has become a popular alternative source to point-scale ground measurements $[7,8]$. While this source is very helpful in understanding the spatial and temporal variability of soil moisture anomalies, its consistency over space and time is hindered by the limited life span of satellites (roughly 5 years, for a given satellite), low temporal resolution (depending on the latitude and satellite orbit, a given location is typically observed every 2-5 days), and vertical penetration (observations typically relate to a $1-5 \mathrm{~cm}$ surface soil moisture layer). There are a number of data evaluation studies that have demonstrated that various sources of datasets come with different known limitations. For instance, the authors of $[5,9]$ showed that the quality of soil moisture anomalies from various existing passive microwave observations drop in quality over densely vegetated areas. The authors of $[5,8]$ also reported a lack of observations due to the impact of radio frequency interferences on some passive microwave observations.

Ideally, a set of high spatial and temporal resolution soil moisture observations would serve as the best option for both scientific research and operational services; however, this is a challenge in the existing observation datasets. Increased knowledge of the climate system and technological advancements have created an avenue for climate variables to be simulated in climate models. This has served as a basis to produce higher spatial and temporal resolutions of variable states as they get more sophisticated to handle the complexities of the climate system. Land surface models (LSMs) have become an additional source of information for various climate variables, such as soil moisture, surface fluxes, and run-off, providing complete global coverage and continuous estimates over time. These are based on mathematical models obtained from an understanding of the climate and its regularities $[10,11]$. Another development in climate modeling is based on the assimilation of observations from both ground and remotely sensed sources into the models to update variable states and understand the impacts and response of the various parameters [12]. This has also allowed for more efficient weather forecasting and climate predictions, although it is heavily reliant on observation as inputs in the assimilation schemes [13]. They have become very helpful for both large- and small-scale uses to observe the interactions within the climate system. Existing globally recognized space and weather organizations have continuously updated their systems based on improved understanding of the uncertainties linked with soil moisture and other physical variables from observations. Furthermore, understanding how these improvements impact the quality of soil moisture estimates is necessary as soil moisture is increasingly being applied in different schemes to explain various land-atmosphere processes.

Several studies have used model-simulated soil moisture estimates to study regions over the globe, where soil moisture impacts the atmosphere significantly [1,4,14]. Additionally, these products have become a reliable source of information within merging schemes of satellite and ground observation datasets as references. For example, the multidecadal global satellite-observed soil moisture dataset developed by the European Space Agency (ESA) as part of its Climate Change Initiative (CCI) relies on soil moisture model estimates as a scaling reference to correct the systematic differences between the active and passive soil moisture datasets used in their combined (active + passive) product $[7,8]$. In another study, the authors of [15] developed an approach to improve the correlation coefficients of satellite soil moisture products based on a linear combination scheme, and it was later temporally extended [16]. Their studies showed how different choices of a range of reference datasets would affect the quality of the final output. Although these merging approaches operate very well, the quality of the final output, the merged soil moisture product, directly depends on the quality of the chosen reference dataset. Since the combination approaches are blind to the limitations within these reference 
datasets, there is a need to evaluate existing products to understand their choices in various climate regions and conditions.

Previous studies were involved in understanding the skill of these soil moisture products, both globally and regionally. The authors of [17] did a global assessment of the land surface hydrology estimates of the latest version of the Modern Era Retrospective Analysis for Research and Applications (models' family name is hereafter referred to as NASA) with two earlier versions and found that the most recent product generally performed better than the other two earlier versions. In another study, Albergel et al. [18] assessed the performance of two generations of the European Centre for Medium-Range Weather Forecasts' atmospheric reanalysis products (models' family name is hereafter referred to as ECMWF) by using them to force a land surface model and their impacts were evaluated with observations. They found that the latest version consistently led to improvements relative to the earlier version. In a more recent study, two versions of the Global Land Data Assimilation System (models' family name is hereafter referred to as NOAA (National Oceanic and Atmospheric Administration)) were also compared by Xia et al. [19], and it was found that the most recent version showed closer soil moisture anomalies compared to ground observations. While these studies have been useful in highlighting the improvements in the newer soil moisture products, their comparisons with in situ datasets were largely restricted to datasets from Europe, Australia, and the US, and did not include China as a whole. This study extends these comparisons through an evaluation of soil moisture anomalies from three independent LSM families (ECMWF, NASA, and NOAA). Here, these data sources are compared against satellite soil moisture products and then with in situ sources over various vegetation scenarios to assess their performances as well as understand the relative improvements in the newer products over the mainland of the People's Republic of China. The modeling systems listed above have been understood by comparison with the same in situ datasets used in the above-cited evaluations. Hence, a detailed evaluation over a region not included in those datasets, such as China, will provide an independent confirmation of the improved skill of the newer generations of each modeling system.

In a previous study, Koster et al. [20] used 12 global climate models to assess the impact of soil moisture anomalies on precipitation globally. They found that while the models agreed on the spatial variabilities of the hotspots of these land-atmosphere interactions, their magnitudes varied largely due to different sensitivities of the models which was possibly due to the high spatially variable nature of soil moisture. Over China, these hotspots were found over regions that were partly wet and partly dry. China is characterized by several climate zones based on the Koppen Geiger climate classifications [21]. This makes it a very suitable regional test bed to fairly assess the performance of these model products without the added noise of the global scale. In this study, we largely rely on the triple collocation technique (TCA) to estimate the error structure of the anomalies of seven model estimates from the three LSM families over the period of 2008 to 2015. The advantage here of using triple collocation is its ability to evaluate the products over the entire areal extent of the study region, so that data quality for the various climate zones can be properly understood. Additionally, vegetation cover and rainfall patterns have been suggested to be partial indicators for the spatial variation of the various climate conditions [22]. Therefore, the TCA analysis employed here gives us the chance to properly understand the relative quality of the soil moisture anomalies of the different LSM products over different vegetation scenarios within the region. It is expected that lessons learned from this regional study will be transferred to global scale studies, since China offers a wide range of different climate scenarios. While the southeastern parts of China have been found to receive more rainfall throughout the year than the rest of the country, the northwestern parts have been reported to be the driest parts of the country [23]. In the rest of the paper, Section 2 introduces the datasets used in this study, Section 3 presents the methods and results, Section 4 discusses the results and their implications, and Section 5 presents the conclusions of the study. 


\section{Materials and Methods}

\subsection{Model Datasets}

Model datasets, which are a great additional source of information, may combine the added advantage of their model states and available remotely sensed datasets and ground observations through data assimilation schemes. The availability of these different products enables extensive operational and scientific research. In this section, three commonly used LSM datasets are presented.

\subsubsection{ECMWF's Reanalysis Datasets}

The ERA datasets used in this study are reanalysis datasets provided by ECMWF. The ERA-Interim dataset is a set of global atmospheric reanalyses that was produced to serve as an improvement on the ERA-40 dataset which is from an earlier project of ECMWF [24]. Like ERA-40, it also uses the TESSEL scheme, which is the land surface component within the forecast model. Within the scheme of the ERA-Interim (ERAI) project, key aspects of ERA-40 data assimilation, such as the quality of circulation within the stratosphere, the representation of the hydrological cycle, and the changes in the observation system, as well as the handling of biases, were improved. Soil moisture estimates within this framework are produced as volumetric soil water content for 4 soil layers. While the earlier version of the atmospheric reanalysis made use of the 3-dimensional variational analysis data assimilation scheme, the ERAI project uses 4-dimensional variational analysis (4-D Var) in addition to an increased number of satellite observations for bias corrections in its atmospheric reanalysis. It has been extensively validated globally and regionally [24].

ERA5, which is the latest atmospheric reanalysis of ECMWF was recently made public. This was also produced using the Integrated Forecast System (IFS) data assimilation and the Earth-system model of ECMWF. The improvements within this dataset include the inclusion of several newly reprocessed observations that were not included in ERAI, higher spatial resolution from $79 \mathrm{~km}$ in horizontal dimension to $31 \mathrm{~km}$, and higher temporal resolutions from $6 \mathrm{~h}$ to $1 \mathrm{~h}$. This has now replaced the ERAI scheme. While it is not as well documented and validated as the ERA-Interim products, recent evaluations have shown its capability to be an important additional source of information [18]. In this study, we explore into details to understand these improvements in soil moisture anomalies. It is hereafter referred to as ERA5. The aggregated 0.25 spatial resolution products of this LSM at 06:00 each day within the period of 2008 to 2015 are used (Copernicus Climate Change Service (C3S) (2017): ERA5: Fifth generation of ECMWF atmospheric reanalysis of the global climate. Copernicus Climate Change Service Climate Data Store (CDS). https://cds.climate.copernicus.eu/cdsapp\#!/home). More details of this product can be found at https://confluence.ecmwf.int/display/CKB/ERA5, and access to data can be found at https://cds.climate.copernicus.eu/cdsapp\#!/home.

\subsubsection{NASA's Reanalysis Datasets}

The Modern Era Retrospective Analysis for Research and Applications (MERRA) is a set of global long-term reanalysis products based on in situ and satellite observations assimilated in the data assimilation system of the National Aeronautics and Space Administration (NASA).

The MERRA project was started to improve the representation of the hydrologic cycle which was found to be inadequate in several earlier reanalysis models. Various types of satellite observations were used in the MERRA scheme, and the various outputs of MERRA have been evaluated both globally and regionally [25]. The earliest generation used in this study is hereafter referred to as MERRA1 in this study.

MERRA-Land [13], another MERRA project, provides improved land surface estimates and flux variables by re-playing the MERRA land surface model in offline (land-only) mode. This replay uses revised model input parameters, and the MERRA model-generated precipitation is corrected toward observations. Previous studies have evaluated this dataset and found it to be an improvement on the 
land surface estimates of the earlier MERRA [26]. The surface soil moisture estimates used from this in this study are hereinafter referred to as MERRALand.

MERRA-2, hereafter referred to as MERRA2, was released to replace the original MERRA reanalysis, and includes various updates to the model, assimilation system, and assimilated observation datasets. Based on lessons from the MERRA-Land project, this dataset was also produced with precipitation forcing, which has been corrected with observations instead of the one generated by the model. In addition, sudden global interannual variations which occur as a result of changes in the observation system have been minimized. In this study, we used the soil moisture estimates which came at a native spatial resolution of $0.5 \times 0.63$ at 03:00 each day.

\subsubsection{NOAA's Datasets}

The Global Land Data Assimilation System was produced at NOAA NCEP (National Centers for Environmental Prediction) and developed in collaboration with NASA. It is an offline system, similar to MERRA-Land. Within this scheme, four land models are used: the community land model (CLM), the variable infiltration capacity model (VIC), the mosaic model, and the Noah model. The goal of this scheme was to integrate satellite and ground-based observations into the models to generate improved land variables. Two versions of the GLDAS-NOAH products are used here: v1 (GLDAS-1), which comes at a resolution of 1.0 and covers the time period from 1979 to the present time and v2.1 (GLDAS-2.1), which comes at a resolution of 0.25 and covers the time period from February 2000 to the present time. The latter was started to replace the former (the 0.25 resolution products). Improvements in v2.1 are as a result of the use of observation-based forcing data. Biases in precipitation which were found in v1 and v2.0 have been corrected in v2.1, which is thus expected to improve soil moisture estimations. In this study, we used the soil moisture estimates from both Noah1.0 and Noah2.1, which will hereafter be referred to as NOAH1.0 and NOAH2.5, respectively. NOAH1.0 was resampled to 0.25 and the chosen time was at 3:00 each day. For more details on these products, readers are referred to Ref. [27].

\subsection{Evaluation Data Sets}

\subsubsection{Ground Observations}

Ground soil moisture observations are generally considered to be the ground truth and the most accurate source of data. They are limited spatially because of their point-scale representations. These point-scale measurements only capture the immediate surroundings of their locations. Despite their hindrances, they provide a great way to validate other sources of soil moisture measurements [28].

China has a vast network of soil moisture ground observations. Two major types of in situ datasets were used in this study to validate the reanalysis datasets over the study region. This study used 119 agro-meteorological stations managed by the China Meteorological Administration over the entire country (Figure 1a). The observations were almost exclusively in the east of the region, with the mountainous and desert west being poorly sampled. This dataset came at a temporal resolution of 10 days within the time period from 2011 to 2013. It represented the first level layer $(0-10 \mathrm{~cm})$ of the soil at each point from wet climate zones through transition, that is partly wet and partly dry climate zones, to dry climate zones. Another set of ground observations used in this study was the first level datasets of the soil moisture observations from automatic stations from the Hebei, Jiangsu, and Jiangxi stations which are located in the east central to southeastern parts of China. These came at an hourly temporal scale over the three provinces. The three provinces were all found over the eastern part of China and in northeast, central east, and southern east of the country, representing wet as well as moderate to dense vegetation areas. These datasets were obtained from the Hebei, Jiangsu, and Jiangxi meteorological agencies. We used the time periods from 2012 to 2014, since more consistent data were found over that period. 
(a) Overview Map

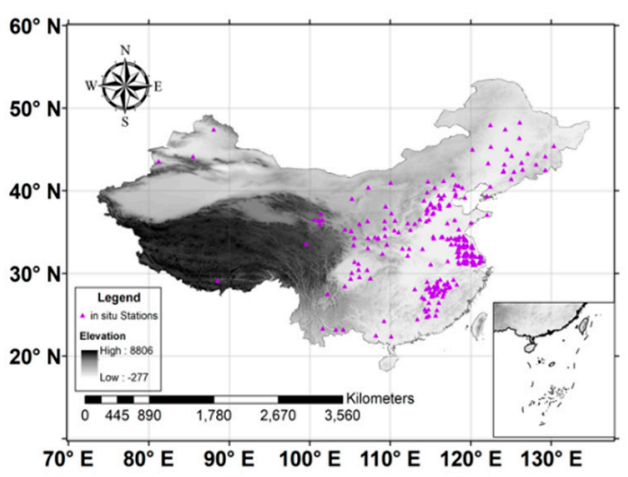

(b) NDVI Distribution over Mainland China

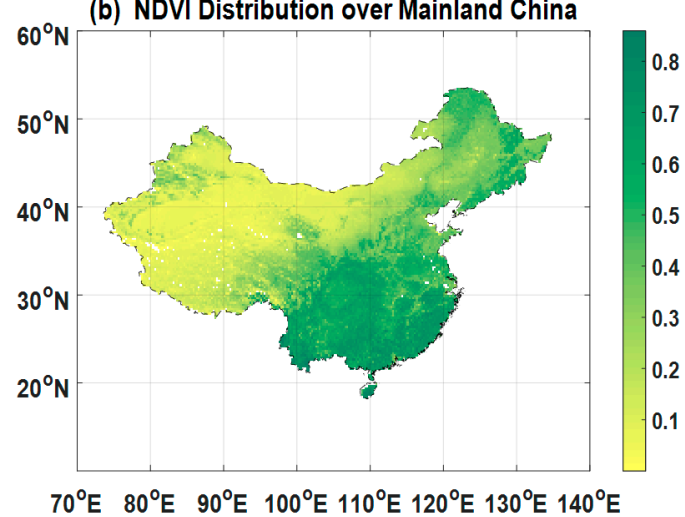

Figure 1. An overview map of the study region showing (a) the soil moisture ground observations and (b) the Normalized Difference Vegetation Index (NDVI) distribution over the region.

\subsubsection{Microwave Satellite Observations}

The ESA CCI Essential Climate Variable (ECV) project has produced long-term satellite soil moisture observations from both passive and active satellite observations (hereafter referred to as ECV products). Over the years, different versions of the ECV products have been developed beginning from [8] to the recent version by [7]. In this study, both the active and passive ECV soil moisture products were used over the period of 2008-2015 at a resolution of 0.25 . The datasets came at a daily scale temporal resolution for both the products. The different versions of the ECV products have already been validated and significant improvements have been reported in the newer versions [7]. Here, we extracted the regional area from the global product to use in an error estimation technique.

\subsubsection{Normalized Difference Vegetation Index}

Previous studies have demonstrated that the quality of soil moisture anomalies varies as a function of vegetation density [9]. In order to quantify the spatial quality of the soil moisture anomalies within the models, we used an independent data source, the Normalized Difference Vegetation Index (NDVI), for a spatial evaluation to quantify the skill of the products over various climate scenarios. In this study, the NDVI data was obtained from the moderate resolution imaging spectrometer, which was used as a vegetation indicator linked to greenness. It was expected that there will be variable qualities of these reanalysis datasets to different scenarios of NDVI. The authors of [22] found that the quality of passive microwave soil moisture observations dropped with increasing vegetation density over this region. Since passive microwave observations are ingested in most of the above models, their characteristics may be transferred into the final products as well. In this study, monthly NDVI were resampled into 0.25 grid binned over the range, $0.1<\mathrm{NDVI}<0.85$, and used to compare against the root-mean-square error from a verification technique and the correlations with the in situ datasets. A spatial overview of the NDVI over the study area is shown in Figure $1 \mathrm{~b}$.

\section{Methodology and Results}

\subsection{Intercomparison with In Situ Data}

We began with a correlation analysis between the in situ datasets and the reanalysis dataset. Figure 2a shows the varying correlations of the LSMs over the different scenarios of NDVI. It can be seen here that the pattern of the quality of the temporal dynamics of the LSMs over the varying ranges of NDVI was very similar. The quality generally increased with increasing vegetation cover with the best quality occurring over moderately dense vegetation cover (i.e., $0.4<\mathrm{NDVI}<0.6$ ). Over the denser vegetation (i.e., $0.6<\mathrm{NDVI}<0.8$ ), the quality drastically reduced. Among the three families of the LSMs, great improvements can be seen between the older and newer versions. NOAH2.5 clearly 
showed higher correlations than NOAH1.0, with much significant improvements in arid and semi-arid conditions in NOAH2.5. These results were in agreement with that obtained by [29], that NOAH1.0 did not demonstrate good skill across arid regions. It was therefore encouraging to see this improvement in NOAH2.5. Among the MERRA and ERA LSM families, the improvements in the newer versions were also seen generally under all the climate conditions. These were in agreement with results obtained by $[17,18]$, who found MERRA2 and ERA5 to be consistently better than their earlier products. While the quality of MERRA1 sharply dropped across moderate to dense vegetation conditions, MERRA2 persisted in good skill over these areas. It was, thus, expected that improvements would generally be seen in the newer products across semi-arid to humid over larger scales. Seeing that most of the newer versions will eventually replace the older versions, it was certainly encouraging to see that the quality of the temporal dynamics of the newer products are more consistent with the ground observations as demonstrated in the correlation analysis in this region.

\section{(a)}

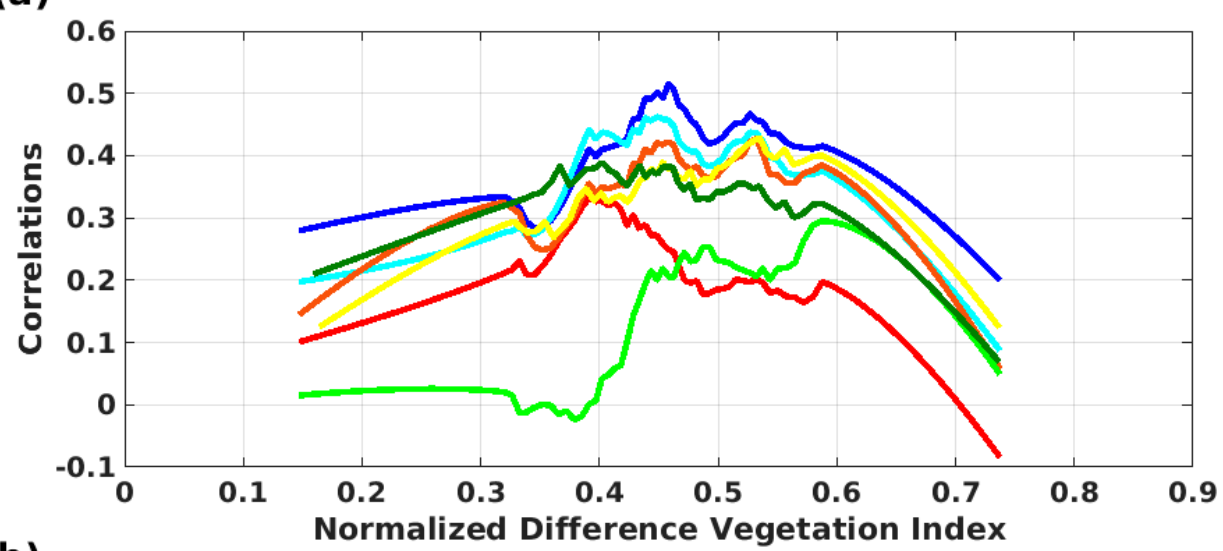

(b)

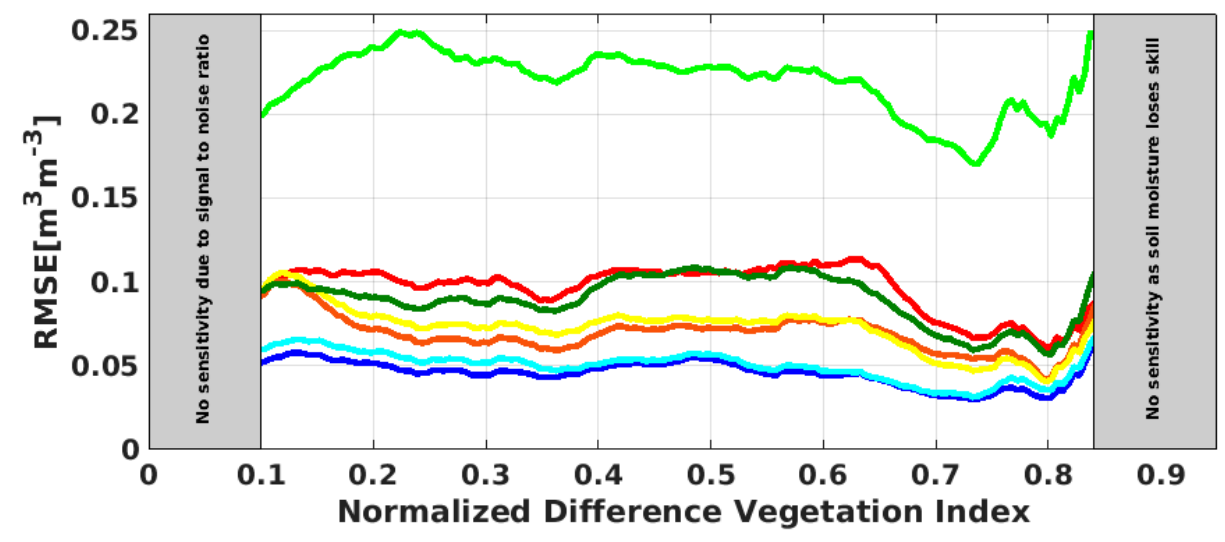

ERA5 - ERAI - MERRA1 $=$ MERRA2 MERRALand $=$ NOAH1.0 NOAH2.5

Figure 2. (a) Validation results for correlation analysis with in situ datasets and (b) Root mean square error (RMSE) results from the triple collocation analysis as a function vegetation density from the normalized difference vegetation index.

\subsection{Triple Collocation Analysis}

Triple collocation analysis (TCA) was developed to intercompare three independent geophysical products in order to quantify their error magnitudes [30]. Since its initial application to validate wind [31], it has also been adapted for use in validation schemes of soil moisture [22,32], soil temperature [33], and precipitation [34]. In its application, the relative error of three products of the same geophysical variable is estimated. The main assumptions in the use of this technique is that the errors of the three products should be uncorrelated (zero cross correlation). Error estimation 
of soil moisture is generally quite difficult to do, and given the scarcity of soil moisture ground observations, it has become necessary to find a way to quantify errors in the existing products outside of the general statistical estimations. Here, the TCA was applied to three products at a time to compute the root-mean-square error (RMSE) of the reanalysis data for each grid point. Within this scheme, we kept the ECV passive and active products fixed as inputs and alternated the reanalysis products as the third TCA input to produce seven TCA RMSE maps for each LSM over the entire region. Over grids where the available observations in the ECV time series was less than 100 time points, we masked it out. It is, therefore, worth noting that the qualities were essentially relative to the ECV soil moisture products. Thus, smaller RMSEs refer to where the two ECV products mostly agree with the quality of the reanalysis products, while larger errors reflect a strong disagreement among the products.

Figure $2 \mathrm{~b}$ shows a first comparison of the soil moisture anomalies from the individual reanalysis datasets based on TCA RMSEs. The RMSE values of the newer versions of the LSMs were smaller than the earlier versions. Generally, their qualities remained steady for NDVI $<0.65$, followed by a quality fluctuation for NDVI $>0.65$. Once again, a tremendous improvement was seen in the NOAH family as the RMSE for NOAH1.0 was considerably larger in all scenarios of NDVI. MERRA2's quality, which was closely tied up with MERRALand, can be attributed to the fact that MERRALand was used in the development of MERRA2. Nonetheless, a significant improvement was seen between MERRA2 and MERRA1 over all scenarios of NDVI. The ECMWF family seemed to maintain very good performance in both error magnitudes and temporal dynamics (correlation) over the different ranges of NDVI scenarios (Figure $2 \mathrm{a}, \mathrm{b}$ ). Overall, parts a and b of Figure 2 complemented each other in explaining the varying qualities over different climate regions. It is, however, worth mentioning that since the satellite observations used in the ECV scheme were also included in the NASA and ECMWF products, this may impact the TCA results. Nonetheless, this goes to highlight the importance of ingesting these satellite observations into models.

Going further into a more detailed analysis of the qualities, we took a step into seeing the performance of the different LSMs over the different climate zones in the region. Soil moisture has been reported to be very inhomogeneous over both space and time [35]. Given that TCA offered a comprehensive analysis of soil moisture anomalies over both space and time, we looked at TCA RMSEs over the different Koppen Geiger climate zones in the region. We divided the zones into four major ones: the dry Northwest Xinjiang-Inner Mongolian region (BB), the transitional Northeast Hubei-Huabei region (DW), the cold regions of the Tibetan Plateau (ET), and the wet Southeast region (CW). In an earlier study over Southwest China, the authors of [36] reported that ERAI demonstrated good skill in capturing the soil moisture dynamics in that region. Their results were confirmed in this study in the CW zone, which includes Southwest China.

Figure 3 shows the performance of the LSMs based on TCA RMSE over the various climate zones. The pattern of the performance of the LSMs was generally similar throughout all the climate zones. Once again, the newer versions portrayed improvements in all the regions. While the lowest error magnitudes were seen over BB, the largest errors were observed over ET. The authors of $[29,37]$ reported the difficulty of both satellite and model products in estimating accurate soil moisture measurements over the Tibetan Plateau. This finding was, thus, in line with previous studies. The transition zone, DW, also showed relatively higher error magnitudes in all the LSMs. The transitional zones, have been reported by previous studies to be the regions of strong land-atmosphere interactions (hotspots) [38]. Figure 3 highlights that since relatively larger errors were observed over the transition zones, their impacts on the atmospheric parameters would be very varied. While these were regional results, they may have merits for global inference since most areas across the globe include the above climate zones. 


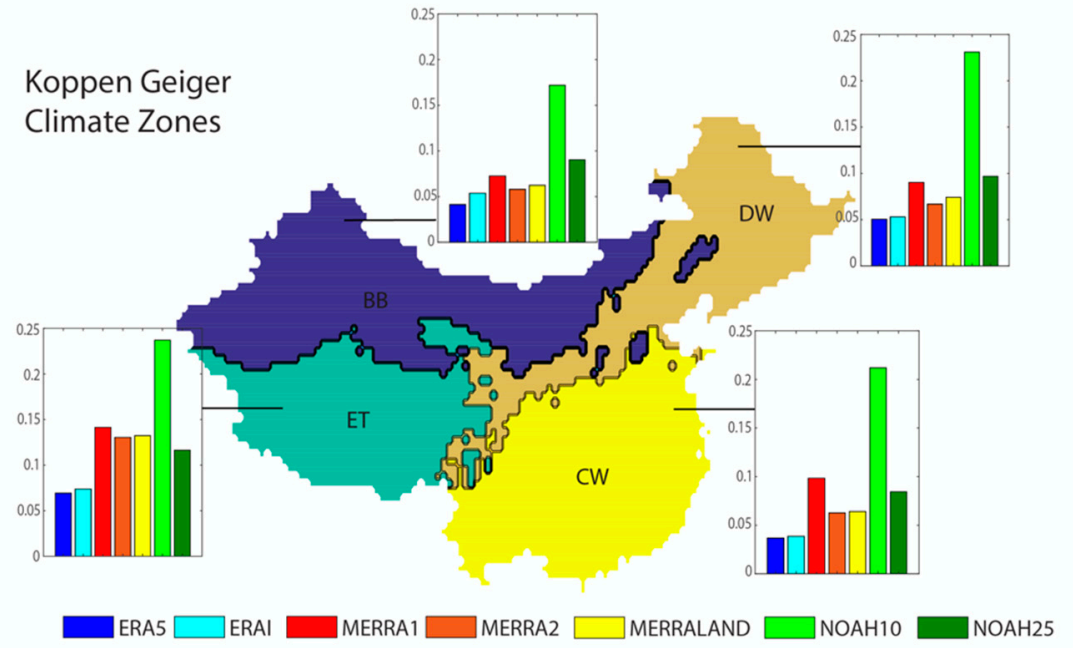

Figure 3. Triple Collocation Analysis (TCA) RMSE results over the different Koppen Geiger climate zones over China for the models.

To demonstrate the level of agreement between the performances of the LSMs, a similarities map based on the variance ratio of their RMSEs (scaled between 0 and 1) is presented in Figure 4, where values higher similarities were implied as the values approached 1 . The spatial similarities map in Figure 4 once again confirmed that the highest disagreement occurred over the transition zones along the DW zone. In the very wet and very dry regions, higher similarities were seen within the LSMs. The ET zone also reported high dissimilarities within the qualities of the LSMs in Figure 4a. Some studies have even suggested the need to develop special datasets tailored to the complexities over the Tibetan Plateau [39]. Furthermore, both the longitudinal and latitudinal cross sections of the RMSEs (Figure $4 b, c$ ) showed that the improvements in the newer versions of the LSMs were evident across both North-South and East-West of China.

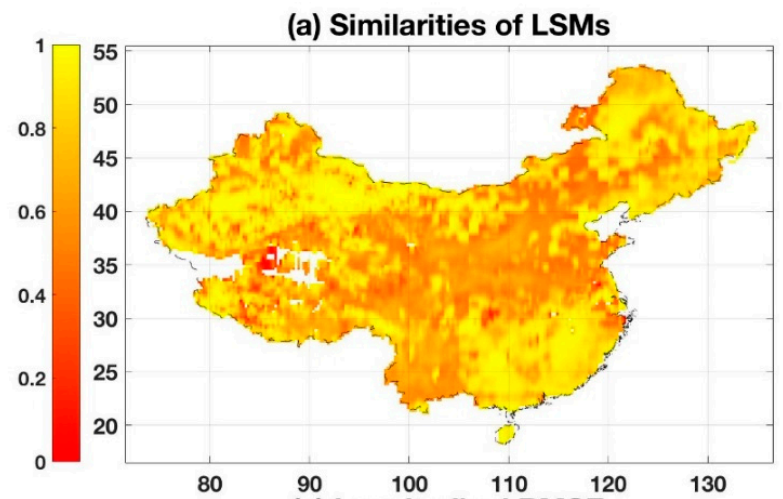

(c) Longitudinal RMSE

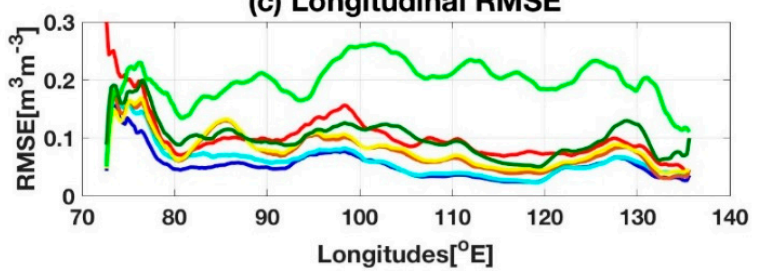

(b) Latitudinal RMSE

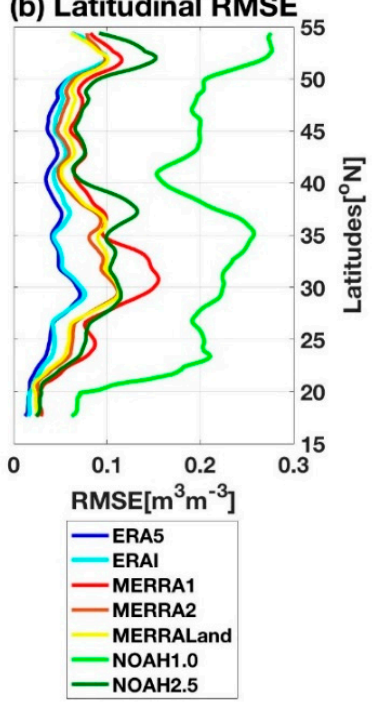

Figure 4. Similarities maps for the seven LSM soil moisture products based on the variance ratio of the TCA RMSEs. (a) shows similarities over the entire region, (b) shows the longitudinal RMSEs and (c) shows the latitudinal RMSEs. 
In order to further investigate these similarities and improvements in the newer generations of the different LSM families, Figure 5 is shown here to give more insights. Figure $5 \mathrm{a}-\mathrm{c}$ shows the similarity maps of the individual LSM families. Figure 5a,b shows that there were very high similarities over the entire study region among the ECMWF and NASA families, although the NASA models showed larger differences over the central parts of the region, mostly due to MERRA1. The NOAA models, on the other hand, showed a considerable difference especially over the transition zones of the region. Since similarities did not imply improvements, we went a step further to compute improvements based on TCA RMSEs of the LSMs. This was computed by subtracting the RMSEs of the newer models from the RMSEs of the older models for each LSM family. The red color implied improvements in the newer versions, while the blue color showed deterioration in quality. Figure $5 \mathrm{~d}$,e shows improvements over most parts of the region, with comparatively more improvements in the NASA products. The improvements in the NASA LSMs were computed between MERRA1 and MERRA2. Obviously, all the analysis, including the correlation analysis with the in situ datasets, showed that there was a very significant improvement in NOAH2.5, not just in terms of higher resolutions, but also in its biases and temporal dynamics as can be seen in Figure $5 f$. These improvements seen in the newer generation of the products are of immense importance, since current and future studies will mostly depend on the newer generations to understand the climate. There has also been a significant improvement in the parameterization schemes of the climate models. Additionally, we can expect more reliable results from the application of these products to understand the climate system.

(a) ECMWF Models Similarity

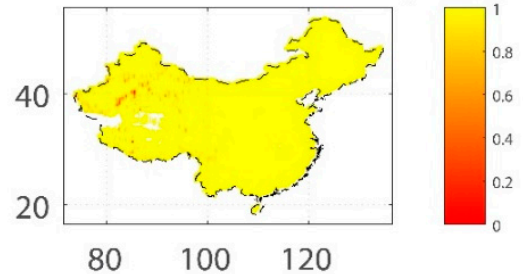

(b) NASA Models Similarity

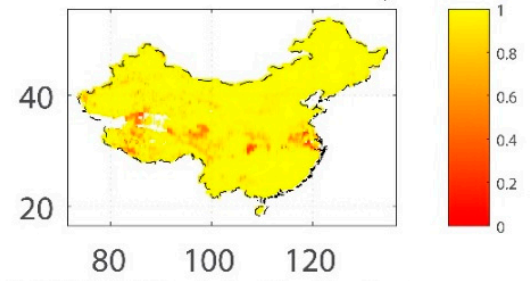

(c) NOAA Models Similarity

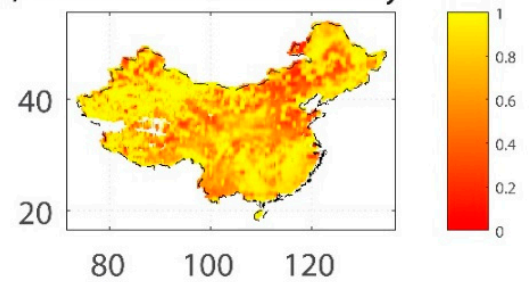

(d) ECMWF Models Improvement

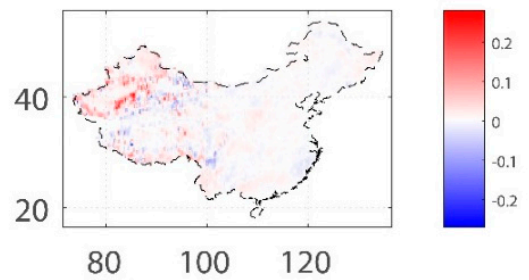

(e) NASA Models Improvement

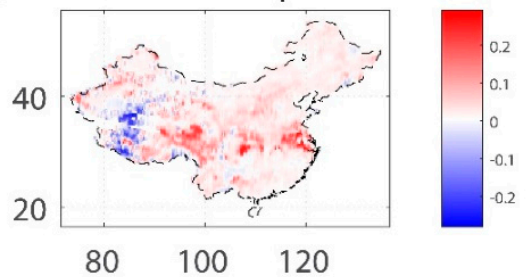

(f) NOAA Models Improvement

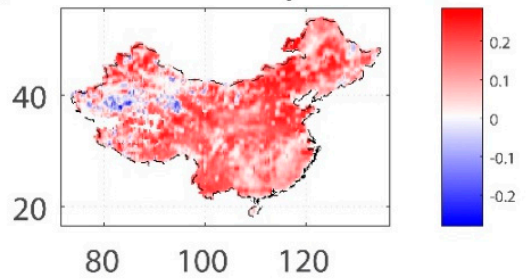

Figure 5. Similarities maps for the three LSM families $(\mathbf{a}-\mathbf{c})$ and their corresponding improvement maps based on TCA RMSEs (d-f), where red represents improvements and blue represents deterioration in quality.

\section{Discussion}

Some earlier studies have reported on the strengths and weaknesses of various reanalysis and model-based soil moisture products over some regions in China [29,36,40,41]. These studies demonstrated the potential of these products to serve as reliable sources of long-term soil moisture variability and their potential applications in research and operational services due to their consistency 
in space and time. This study has sought to assess the performance of reanalysis/analysis soil moisture products over China based on both point-scale ground observations and grid-averaged satellite soil moisture products. In an attempt to see the agreement between the two validation techniques used (Figure 6), we directly compared only the results from the latest versions of the three LSM families (ERA5, MERRA2, and NOAH2.5) by matching TC RMSEs over the in situ locations with the correlation results. To better extrapolate their relationship, they were smoothed out. The analysis showed that all three of them had an inverse relationship, with the highest agreement found in the ERA5 product (R: -0.93). A recent study which assessed satellite and reanalysis products over the Tibetan Plateau region of China also reported the reliability of ERA5 soil moisture product [42], confirming the results obtained in this study. The colors of the plots in Figure 6 correspond to NDVI densities. Generally, places of higher correlations of the LSMs with the in situ also showed small RMSEs from the triple collocation, while smaller correlations occurred over locations with higher RMSEs. This was more distinct over areas with moderate to low vegetation densities, which is consistent with previous results reported in [40], which also reported the good skill of MERRA2 and NOAH over different vegetation scenarios although their study focused on a smaller region in China. These add up to imply a similar relative skill of the products in this study region. Furthermore, the similarities with Figure 2 demonstrated that we can rely on these two analyses to understand the qualities of these datasets. This comparison in Figure 6 also gave us a wider view of the quality of these products and the reliability of the ECV products used in the study. Consequently, the encouraging results obtained in this study, especially from the newer products is evidence of progress in our understanding of the climate system. As mentioned before, due to China's vastness, it covers a wide range of climate scenarios that allow us to explore the skill of these products without the added noise of the global scale. Therefore, it is expected that the lessons learned here may be useful in calibrating both regional and global climate model schemes, though this should be done with caution.

(a) ERA5

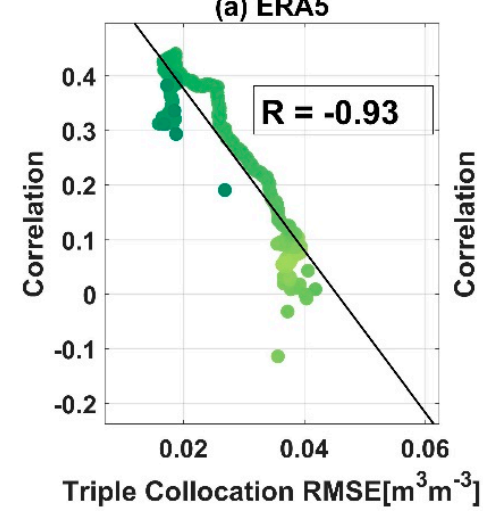

(b) MERRA2

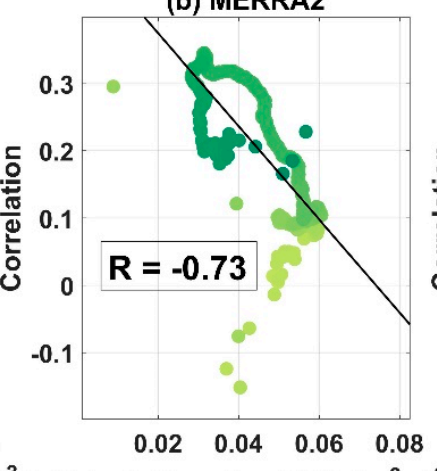

(c) NOAH2.5

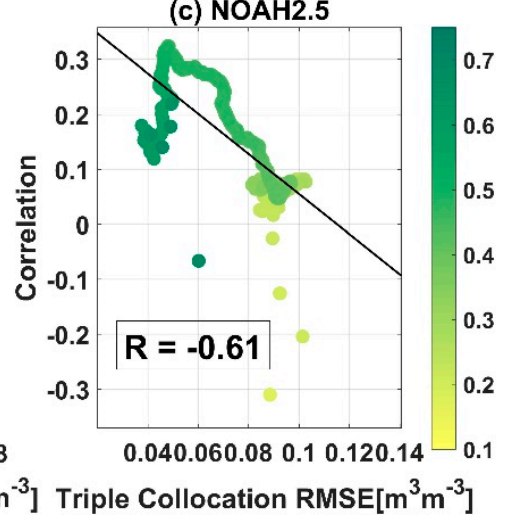

Figure 6. A direct comparison between the correlation and triple collocation analyses of (a) ERA5, (b) MERRA2 and (c) NOAH by matching TC RMSEs over the in situ locations. The colors correspond to vegetation densities over the region.

Soil water content from satellite observations over China has been reported to increase from west to east, mostly due to precipitation distribution in the region [22]. As seen in the Koppen Geiger climate zone map, the ET and BB regions have relatively dryer climates than DW and CW, especially the latter regions have been shown to be wetter climate zones. Precipitation is more predominant over the CW zone and soil moisture distributions in this region have the highest estimates. Figure 7 shows how all the models reflected the west-east soil moisture variability. All the newer generations showed that they were able to capture the west-east pattern with lower soil moisture content in the west and increasing soil moisture content eastwards. NOAH1.0, on the other hand, showed an opposite pattern, with much lower soil moisture estimates in the east and comparatively higher estimates in the west. This is very 
essential to studies on both local and non-local interactions of soil moisture on other climate variables and processes.

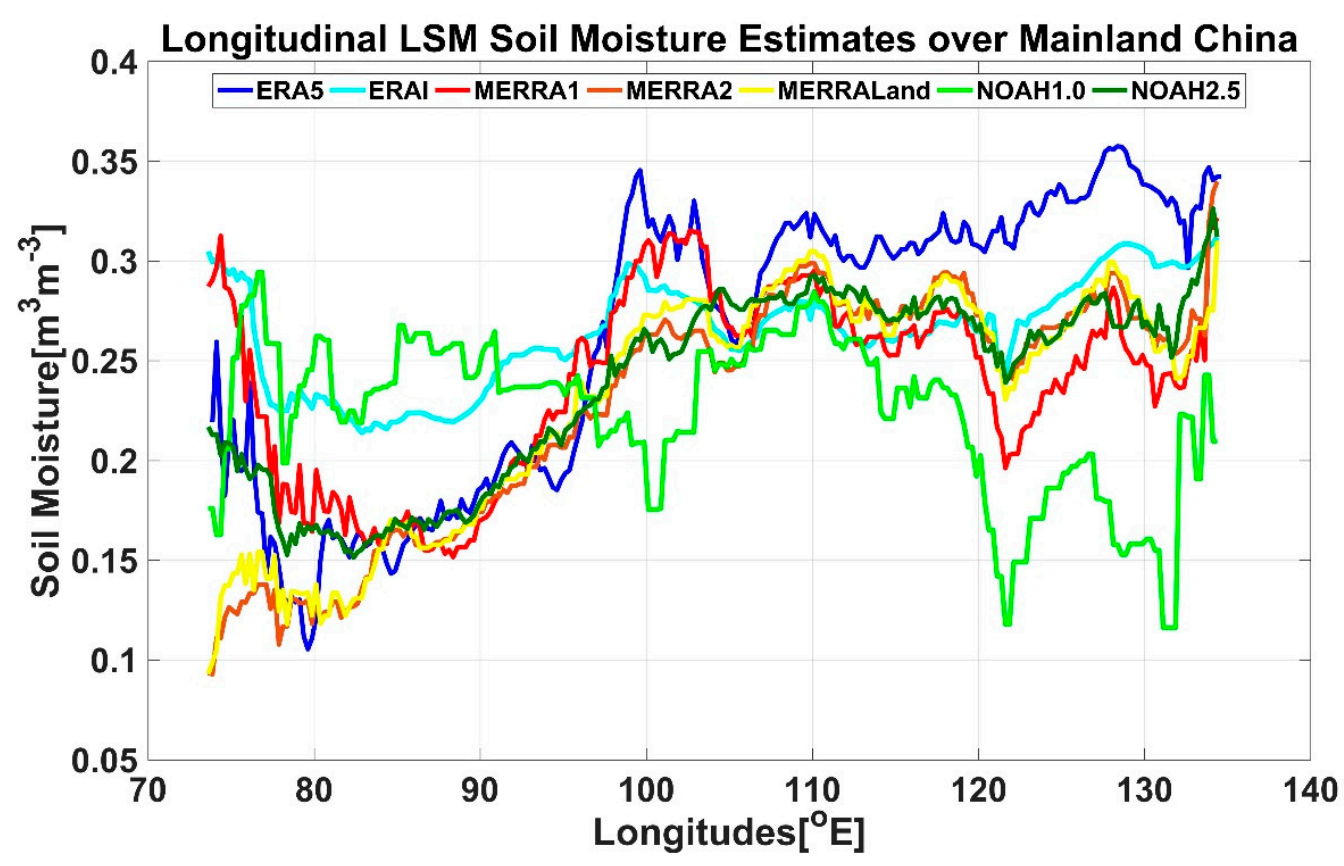

Figure 7. The longitudinal variability (west-east pattern) of soil moisture estimates from the LSMs.

\section{Conclusions}

This study evaluated soil moisture product estimates from seven commonly used land models from three different reanalysis model schemes (LSMs) over the entire region of China. Two independent validation techniques were used to assess their qualities: correlation analysis and root-mean-square error based on triple collocation analysis (TCA RMSE). The correlation comparison with the in situ datasets showed that all the LSMs had fluctuating correlations up to 0.6 , with all the newer generations of the LSMs performing better than their older generations. When validated against an independent vegetation data source, NDVI, the results demonstrated that the correlations of all the LSMs dropped over very dense regions. Additionally, a detailed look at the TCA RMSE outputs also indicated consistent improvements in the newer generations of the LSMs over their earlier versions. Over different NDVI ranges, much like the correlation drop, the error magnitudes increased over dense vegetation (NDVI > 0.65). The densely vegetated areas were also regions of high precipitation distribution in China, thus, there may a need for the modeling agencies to focus on improving both the vegetation and precipitation schemes within the models. Across the different climate zones defined with the Koppen Geiger classifications, the regions over the Tibetan plateau and the partly wet and partly dry climate zones showed higher magnitudes of errors than the wet and dry climate zones. A further look at the TCA RMSE results also demonstrated that all the newer generations showed higher agreements in their quality over this region, which was consistent with the results of some recent studies. Overall, the ECMWF products showed the highest correlations and lowest RMSEs throughout the entire study, which was in agreement with earlier studies. Very significant improvements were seen in both the NASA and NOAA products. Understanding the performance of these different LSM soil moisture products offers a platform to properly use them and better understand the role of soil moisture within the climate system. While this was a regional result, it covered a wide spectrum of the dominant climate zones across the globe and may therefore hold transferrable merits to regions that have been understudied. This is expected to give the modeling community a good feedback to understand where revisions may be necessary in their modeling schemes. Furthermore, the results demonstrated that these products may provide more reliable results in research and operational applications. 
Author Contributions: Conceptualization, D.F.T.H. and R.M.P.; methodology, D.F.T.H. and R.M.P.; validation, D.F.T.H., R.M.P., and C.S.D.; formal analysis, D.F.T.H., R.M.P., and C.S.D.; investigation, D.F.T.H., R.M.P., and C.S.D.; resources, G.W. and R.M.P.; writing—original draft preparation, D.F.T.H.; writing—review and editing, D.F.T.H., R.M.P., C.S.D., and G.W.; visualization, D.F.T.H. and R.M.P.; supervision, R.M.P., C.S.D., and G.W.; project administration, G.W. and R.M.P.; funding acquisition, G.W. and R.M.P. All authors have read and agreed to the published version of the manuscript.

Funding: This research was funded by the National Key Research and Development Program of China, grant number 2017YFA0603701; the National Natural Science Foundation of China grant numbers, 41875094 and 41850410492; and the Sino-German Cooperation Group Project (GZ1447).

Acknowledgments: We are very grateful to the teams at NASA, NOAA, ECMWF, and TU Vienna who have made their datasets available and ready to use. We are also very grateful to the Hebei, Jiangxi, Jiangsu, and China Meteorological Administrations for providing their data as well.

Conflicts of Interest: The authors declare no conflicts of interest.

\section{References}

1. Hagan, D.F.T.; Wang, G.; Liang, X.S.; Dolman, H.A.J. A Time-Varying Causality Formalism Based on the Liang-Kleeman Information Flow for Analyzing Directed Interactions in Nonstationary Climate Systems. J. Clim. 2019, 32, 7521-7537. [CrossRef]

2. Schwingshackl, C.; Hirschi, M.; Seneviratne, S.I. Quantifying Spatiotemporal Variations of Soil Moisture Control on Surface Energy Balance and Near-Surface Air Temperature. J. Clim. 2017, 30, 7105-7124. [CrossRef]

3. Vogel, M.; Zscheischler, J.; Seneviratne, S. Varying soil moisture-atmosphere feedbacks explain divergent temperature extremes and precipitation projections in central Europe. Earth Syst. Dyn. 2018, 9, 1107-1125. [CrossRef]

4. Hauser, M.; Orth, R.; Seneviratne, S.I. Role of soil moisture versus recent climate change for the 2010 heat wave in western Russia. Geophys. Res. Lett. 2016, 43, 2819-2826. [CrossRef]

5. Parinussa, R.; Lakshmi, V.; Johnson, F.; Sharma, A. Comparing and Combining Remotely Sensed Land Surface Temperature Products for Improved Hydrological Applications. Remote Sens. 2016, 8, 162. [CrossRef]

6. Dorigo, W.A.; Gruber, A.; De Jeu, R.A.M.; Wagner, W.; Stacke, T.; Loew, A.; Albergel, C.; Brocca, L.; Chung, D.; Parinussa, R.M.; et al. Evaluation of the ESA CCI soil moisture product using ground-based observations. Remote Sens. Environ. 2015, 162, 380-395. [CrossRef]

7. Dorigo, W.; Wagner, W.; Albergel, C.; Albrecht, F.; Balsamo, G.; Brocca, L.; Chung, D.; Ertl, M.; Forkel, M.; Gruber, A.; et al. ESA CCI Soil Moisture for improved Earth system understanding: State-of-the art and future directions. Remote Sens. Environ. 2017, 203, 185-215. [CrossRef]

8. Liu, Y.Y.; Parinussa, R.M.; Dorigo, W.A.; de Jeu, R.A.M.; Wagner, W.; van Dijk, A.I.J.M.; McCabe, M.F.; Evans, J.P. Developing an improved soil moisture dataset by blending passive and active microwave satellite-based retrievals. Hydrol. Earth Syst. Sci. 2011, 15, 425-436. [CrossRef]

9. Parinussa, R.M.; Meesters, A.G.C.A.; Liu, Y.Y.; Dorigo, W.; Wagner, W.; Jeu, R.A.M.d. Error Estimates for Near-Real-Time Satellite Soil Moisture as Derived From the Land Parameter Retrieval Model. IEEE Geosci. Remote Sens. Lett. 2011, 8, 779-783. [CrossRef]

10. Koster, R.D.; Guo, Z.; Yang, R.; Dirmeyer, P.A.; Mitchell, K.; Puma, M.J. On the Nature of Soil Moisture in Land Surface Models. J. Clim. 2009, 22, 4322-4335. [CrossRef]

11. Xia, Y.; Mocko, D.; Huang, M.; Li, B.; Rodell, M.; Mitchell, K.E.; Cai, X.; Ek, M.B. Comparison and Assessment of Three Advanced Land Surface Models in Simulating Terrestrial Water Storage Components over the United States. J. Hydrometeorol. 2017, 18, 625-649. [CrossRef]

12. Han, X.; Li, X.; He, G.; Kumbhar, P.; Montzka, C.; Kollet, S.; Miyoshi, T.; Rosolem, R.; Zhang, Y.; Vereecken, H.; et al. DasPy 1.0 - the Open Source Multivariate Land Data Assimilation Framework in combination with the Community Land Model 4.5. Geosci. Model Dev. Discuss. 2015, 2015, 7395-7444. [CrossRef]

13. Reichle, R.H.; Koster, R.D.; Lannoy, G.J.M.D.; Forman, B.A.; Liu, Q.; Mahanama, S.P.P.; Touré, A. Assessment and Enhancement of MERRA Land Surface Hydrology Estimates. J. Clim. 2011, 24, 6322-6338. [CrossRef]

14. Gevaert, A.I.; Miralles, D.G.; de Jeu, R.A.M.; Schellekens, J.; Dolman, A.J. Soil Moisture-Temperature Coupling in a Set of Land Surface Models. J. Geophys. Res. Atmos. 2018, 123, 1481-1498. [CrossRef] 
15. Kim, S.; Parinussa, R.M.; Liu, Y.Y.; Johnson, F.M.; Sharma, A. A framework for combining multiple soil moisture retrievals based on maximizing temporal correlation. Geophys. Res. Lett. 2015, 42, 6662-6670. [CrossRef]

16. Kim, S.; Parinussa, R.; Liu, Y.; Johnson, F.; Sharma, A. Merging Alternate Remotely-Sensed Soil Moisture Retrievals Using a Non-Static Model Combination Approach. Remote Sens. 2016, 8, 518. [CrossRef]

17. Reichle, R.H.; Draper, C.S.; Liu, Q.; Girotto, M.; Mahanama, S.P.P.; Koster, R.D.; Lannoy, G.J.M.D. Assessment of MERRA-2 Land Surface Hydrology Estimates. J. Clim. 2017, 30, 2937-2960. [CrossRef]

18. Albergel, C.; Dutra, E.; Munier, S.; Calvet, J.C.; Munoz-Sabater, J.; de Rosnay, P.; Balsamo, G. ERA-5 and ERA-Interim driven ISBA land surface model simulations: Which one performs better? Hydrol. Earth Syst. Sci. 2018, 22, 3515-3532. [CrossRef]

19. Xia, Y.; Hao, Z.; Shi, C.; Li, Y.; Meng, J.; Xu, T.; Wu, X.; Zhang, B. Regional and Global Land Data Assimilation Systems: Innovations, Challenges, and Prospects. J. Meteorol. Res. 2019, 33, 159-189. [CrossRef]

20. Koster, R.D.; Dirmeyer, P.A.; Guo, Z.; Bonan, G.; Chan, E.; Cox, P.; Gordon, C.T.; Kanae, S.; Kowalczyk, E.; Lawrence, D.; et al. Regions of Strong Coupling Between Soil Moisture and Precipitation. Science 2004, 305, 1138-1140. [CrossRef]

21. Chen, T.; Zhang, H.; Chen, X.; Hagan, D.F.; Wang, G.; Gao, Z.; Shi, T. Robust drying and wetting trends found in regions over China based on Köppen climate classifications. J. Geophys. Res. Atmos. 2017, 122, 4228-4237. [CrossRef]

22. Parinussa, R.; Wang, G.; Liu, Y.; Hagan, D.; Lin, F.; van der Schalie, R.; de Jeu, R. The Evaluation of Single-Sensor Surface Soil Moisture Anomalies over the Mainland of the People's Republic of China. Remote Sens. 2017, 9, 149. [CrossRef]

23. Fu, C.; Jiang, Z.; Guan, Z.; He, J.; Xu, Z. Regional Climate Studies of China; Springer Science and Business Media: New York, NY, USA, 2008.

24. Dee, D.P.; Uppala, S.M.; Simmons, A.J.; Berrisford, P.; Poli, P.; Kobayashi, S.; Andrae, U.; Balmaseda, M.A.; Balsamo, G.; Bauer, P.; et al. The ERA-Interim reanalysis: Configuration and performance of the data assimilation system. Q. J. R. Meteorol. Soc. 2011, 137, 553-597. [CrossRef]

25. Bosilovich, M.G.; Robertson, F.R.; Chen, J. Global Energy and Water Budgets in MERRA. J. Clim. 2011, 24, 5721-5739. [CrossRef]

26. Yi, Y.; Kimball, J.S.; Jones, L.A.; Reichle, R.H.; McDonald, K.C. Evaluation of MERRA Land Surface Estimates in Preparation for the Soil Moisture Active Passive Mission. J. Clim. 2011, 24, 3797-3816. [CrossRef]

27. Rodell, M.; Houser, P.R.; Jambor, U.; Gottschalck, J.; Mitchell, K.; Meng, C.-J.; Arsenault, K.; Cosgrove, B.; Radakovich, J.; Bosilovich, M.; et al. The Global Land Data Assimilation System. Bull. Am. Meteorol. Soc. 2004, 85, 381-394. [CrossRef]

28. Crow, W.T.; Berg, A.A.; Cosh, M.H.; Loew, A.; Mohanty, B.P.; Panciera, R.; de Rosnay, P.; Ryu, D.; Walker, J.P. Upscaling sparse ground-based soil moisture observations for the validation of coarse-resolution satellite soil moisture products. Rev. Geophys. 2012, 50. [CrossRef]

29. Ullah, W.; Wang, G.; Gao, Z.; Hagan, D.F.T.; Lou, D. Comparisons of remote sensing and reanalysis soil moisture products over the Tibetan Plateau, China. Cold Reg. Sci. Technol. 2018, 146, 110-121. [CrossRef]

30. Yilmaz, M.T.; Crow, W.T. Evaluation of Assumptions in Soil Moisture Triple Collocation Analysis. J. Hydrometeorol. 2014, 15, 1293-1302. [CrossRef]

31. McColl, K.A.; Vogelzang, J.; Konings, A.G.; Entekhabi, D.; Piles, M.; Stoffelen, A. Extended triple collocation: Estimating errors and correlation coefficients with respect to an unknown target. Geophys. Res. Lett. 2014, 41, 6229-6236. [CrossRef]

32. Draper, C.; Reichle, R.; de Jeu, R.; Naeimi, V.; Parinussa, R.; Wagner, W. Estimating root mean square errors in remotely sensed soil moisture over continental scale domains. Remote Sens. Environ. 2013, 137, 288-298. [CrossRef]

33. McColl, K.A.; Roy, A.; Derksen, C.; Konings, A.G.; Alemohammed, S.H.; Entekhabi, D. Triple collocation for binary and categorical variables: Application to validating landscape freeze/thaw retrievals. Remote Sens. Environ. 2016, 176, 31-42. [CrossRef]

34. Alemohammad, H.; McColl, K.; Konings, A.; Entekhabi, D.; Stoffelen, A. Characterization of precipitation product errors across the US using multiplicative Triple Collocation. Hydrol. Earth Syst. Sci. 2015, 19, 3489-3503. [CrossRef] 
35. Gouweleeuw, B.; van Dijk, A.; Guerschman, J.; Dyce, P.; Jeu, R.A.M.; Owe, M. Space-based passive microwave soil moisture retrievals and the correction for a dynamic open water fraction. Hydrol. Earth Syst. Sci. Discus. 2012, 9, 1013-1039. [CrossRef]

36. Peng, J.; Niesel, J.; Loew, A.; Zhang, S.; Wang, J. Evaluation of Satellite and Reanalysis Soil Moisture Products over Southwest China Using Ground-Based Measurements. Remote Sens. 2015, 7, 15729-15747. [CrossRef]

37. Su, Z.; Wen, J.; Dente, L.; van der Velde, R.; Wang, L.; Ma, Y.; Yang, K.; Hu, Z. The Tibetan Plateau observatory of plateau scale soil moisture and soil temperature (Tibet-Obs) for quantifying uncertainties in coarse resolution satellite and model products. Hydrol. Earth Syst. Sci. 2011, 15, 2303-2316. [CrossRef]

38. Seneviratne, S.I.; Corti, T.; Davin, E.L.; Hirschi, M.; Jaeger, E.B.; Lehner, I.; Orlowsky, B.; Teuling, A.J. Investigating soil moisture-climate interactions in a changing climate: A review. Earth Sci. Rev. 2010, 99, 125-161. [CrossRef]

39. Zeng, J.; Li, Z.; Chen, Q.; Bi, H.; Qiu, J.; Zou, P. Evaluation of remotely sensed and reanalysis soil moisture products over the Tibetan Plateau using in-situ observations. Remote Sens. Environ. 2015, 163, 91-110. [CrossRef]

40. Fan, K.; Zhang, Q.; Shi, P.; Sun, P.; Yu, H. Evaluation of remote sensing and reanalysis soil moisture products on the Tibetan Plateau. Dili Xuebao Acta Geogr. Sin. 2018, 73, 1778-1791. [CrossRef]

41. Lou, D.; Wang, G.; Shan, C.; Hagan, D.F.T.; Ullah, W.; Shi, D. Changes of Soil Moisture from Multiple Sources during 1988-2010 in the Yellow River Basin, China. Adv. Meteorol. 2018, 2018, 14. [CrossRef]

42. Cheng, M.; Zhong, L.; Ma, Y.; Zou, M.; Ge, N.; Wang, X.; Hu, Y. A Study on the Assessment of Multi-Source Satellite Soil Moisture Products and Reanalysis Data for the Tibetan Plateau. Remote Sens. 2019, 11, 1196. [CrossRef]

(C) 2019 by the authors. Licensee MDPI, Basel, Switzerland. This article is an open access article distributed under the terms and conditions of the Creative Commons Attribution (CC BY) license (http://creativecommons.org/licenses/by/4.0/). 